\title{
The Challenge of Communication in Pandemic
}

\author{
Sangkyun Kim
}

Citation: Kim, S. The Challenge of Communication in Pandemic. Sustainability 2021, 13, 4611. https:/ / doi.org/10.3390/su13094611

Received: 2 March 2021

Accepted: 30 March 2021

Published: 21 April 2021

Publisher's Note: MDPI stays neutral with regard to jurisdictional claims in published maps and institutional affiliations.

Copyright: (C) 2021 by the author. Licensee MDPI, Basel, Switzerland. This article is an open access article distributed under the terms and conditions of the Creative Commons Attribution (CC BY) license (https:/ / creativecommons.org/licenses/by/ $4.0 /)$.
Department of Industrial Engineering, Kangwon National University, Chuncheon 24341, Korea; saviour@kangwon.ac.kr

COVID-19, the first cases of which were reported at the beginning of 2020, has significantly impacted the world. Seemingly, the global economy in 2020 and 2021 will not record any economic growth. Further, it is predicted that the pre-COVID-19 GDP level will not be reached until at least 2022. In a recent survey of more than 200 organisations across the world, McKinsey \& Company reported that more than $90 \%$ of the executives expected that the COVID-19 impact would radically change the way they conduct business over the next five years.

Human beings are changing their way of life at a time when growth is halted and their survival is threatened. To be more precise, it is more of a revolution than a change. We have considered in-person meetings as the best means of communication. Apparently, the best way of life was to meet, communicate, learn, and work together in offices, classrooms, cafes, restaurants, and parks. However, COVID-19 has made it difficult for us to stay together in one physical space. In the context of this situation, the keywords that soared in search volumes in 2020 include non-face-to-face, non-contact, and remote. The distance between social relations and communication is kept as close as possible. However, various measures have been devised to increase physical distance. There are many factors to be discussed with regard to the devised measures, such as their effectiveness and validity and whether the members of our society agree with them or not. However, it is clear that they are creating tremendous change and innovation throughout the world.

Generally, innovation is divided into two types: innovation by companies using new technology and innovation generated by market demand. Therefore, the main agents of innovation are companies and markets. Innovation generated by companies through technology is called technology-push innovation, and innovation driven by market demand is called market-pull innovation.

Technology-push innovation is a theory that asserts that basic science and applied engineering advance and induce new innovations. This is an engineering approach. It is a way for scientists and engineers to develop new technologies and apply them commercially to supply new products and services to the market. It is patent that a customer is left out of the market if the customer does not need the new product. The first cars to be equipped with gasoline engines were made by Carl Benz in 1886. They were built using a gasoline engine created by Nicolaus Otto. The top speed of the cars was about $16 \mathrm{~km} / \mathrm{h}$, which is approximately 1/3-1/4 of the speed at which a horse runs. To run for $100 \mathrm{~km}$, their parts should be cleaned and replaced in the middle of the road. At that time, people were amazed by the car, but considered it impractical in terms of functionality and convenience. This was attributed to the thought that a carriage was enough to carry them and transport cargoes. The first cars have come a long way through continuous innovation, hence overcoming the market's speculation.

Market-pull innovation is a theory that states that market demand and the market environment induce the development of new technology and innovation. The logic is that products and services that meet the new needs of customers are defined, and necessary technologies and business methods developed, to satisfy them. Historically, vaccine development has been mostly a market pull. The desire of humanity to escape the burden of diseases continues to drive the production of new vaccines. For example, smallpox, which 
was spread to the New World by Columbus, claimed the lives of approximately 500 million people, which accounts for $95 \%$ of the Native Americans. Measles claimed the lives of one-third of the population of Athens in the 5th century BC. Humans have, therefore, been constantly researching vaccines whenever a new virus emerges, ever since Edward Jenner created the first smallpox vaccination at the end of the 18th century. Basic human survival instincts create absolute market demand and induce continuous innovation. COVID-19 is driving innovation not only in vaccine research but also in new ways of communicating, working, and conducting business inside and outside the organisation.

COVID-19 is rapidly changing our society as a whole through ways to increase physical distance while keeping the distance between social relations and communication as close as possible. Accordingly, massive innovations in communication among members of the society, as well as the in the way work and education are conducted and how space is utilized, are underway. Attempts to create new workplaces, schools, and play spaces in the virtual world by using various remote communication tools and online platforms are continuing. The communication between members of the organisation has changed remotely. Moreover, a major change is occurring in the methods of communication with customers in terms of marketing and sales. Overall, the space of communication is switching from a physical space to a virtual space based on digital media, such as smartphones, computers, and the Internet.

Some examples of creating new means of communication and economic systems are as follows. First, let us consider Zepeto. Zepeto is a platform that combines augmented reality with lifelogging and a virtual world. It provides a powerful avatar service by combining 3D technology and augmented reality. At Zepeto, users have 3D avatars that are modelled after themselves, engage in social media activities, interact with other users in the virtual world, or play games. Zepeto also provides a marketplace platform. People can use the studio features provided by Zepeto to create a variety of clothes and other items. People can further decide to use the created items or sell the items to other people to earn profits. Users can create event spaces where avatars can communicate and enjoy themselves. Although communication through existing social media is not in real time and a one-to-many method, Zepeto is expanding the experience so that multiple users can communicate in small groups and one-on-one in real time.

Second, let us consider Fortnite. Fortnite is a gaming platform created and operated by Epic Games. However, Fortnite made a very unique move in response to the spread of COVID-19. In April 2020, Fortnite held a concert by celebrity rapper Travis Scott on its own platform. The performance was conducted using the entire Fortnite as the stage. As the opening song rang out, Scott appeared in the shape of a giant, and changed his appearance every time the song changed. In some songs, a dynamic image of Scott and Fortnite users avatars flying into space was created. A total of 12.3 million users participated in the concert that day. Additionally, Fortnite began distributing products using intellectual property rights, such as Nike and Marvel, within its platform. This was an attempt to bring real-world products into Fortnite. As of May 2020, the number of visitors to Fortnite exceeded 350 million. Epic Games is unlikely to leave Fortnite as a simple game platform. Epic Games, the creator of Fortnite, has already announced its intentions to make Fortnite more than a game.

Third, let us examine the case of Zoom, a videoconferencing service that has risen rapidly. Zoom provides features such as remote video conferencing, chat, electronic voting, and small group discussions based on the Internet. Most of Zoom's features were basically developed for the purpose of corporate video conferencing. However, since COVID-19, it has been the most preferred platform by educational institutions in various countries for online classes. Until 2019, before COVID-19, the proportion of remote and contactless education was very low. For example, online lectures at Korean universities in 2019 accounted for only $0.92 \%$. As schools switched from classroom education to contactless online interactions using Zoom, differences began to be observed in the way each institution and educator manages their classes. When classes were held in their own classrooms, it 
was difficult to see how each class was held differently. However, it began to become obvious how we had been teaching over the decades as the classrooms were moved online and teaching methods recorded and shared.

Gartner predicted the change in the way companies would work after COVID-19 by dividing it into several major categories. The first of these is the prediction that the share of teleworking will increase. It states that the ratio of telecommuting was about $30 \%$ before COVID-19, but later increased to $48 \%$. The second is the forecast that companies will collect and analyse business-related data more than ever before. It is expected that companies will more closely collect and analyse the usage history of e-mails and computers in order to accurately determine the work of employees and improve their productivity. This prediction is similar to that made in Korea. According to the "Remote Working Utilisation Survey" released by the Ministry of Employment and Labor in September 2020, $48.8 \%$ of workplaces introduced teleworking due to COVID-19. Of these, $51.8 \%$ said they would continue implementing telecommuting even after the end of COVID-19 or at least implement it among some employees.

The members of the society gave both positive and negative responses with regard to these changes. In the United States, employees who work in the form of telecommuting are $57 \%$ more satisfied than the average American. Regarding the stress level of working hours, $80 \%$ of the respondents answered "not very stressed" and "normal". According to data from Saramin HR's survey of 1925 office workers in Korea, $66.5 \%$ of the respondents were positive about the change in work style due to COVID-19, which was twice as many as those that gave negative answers (33.5\%). When considering the subjects who gave affirmative answers based on age group, those in their $30 \mathrm{~s}$ were the largest group, with $70.1 \%$, followed by those in their $20 \mathrm{~s}(65.2 \%), 40 \mathrm{~s}(62.7 \%)$, and $50 \mathrm{~s}$ or older $(59.8 \%)$. Overall, the satisfaction level with the changed work style decreased as the age increased. Additionally, there were many opinions that remote and contactless work methods undermined the sense of solidarity among members.

The kind of positive and negative consequences of change and innovation attempts undertaken by various organisations to respond to and overcome COVID-19, and the members that will be more impacted by the change, are still unclear. However, in order to survive in a rapidly changing environment, sustainable change and innovation must be constantly attempted. Individuals and organizations who continue to use previous methods in how to manage an organization, how to deal with customers, and how to help people learn and grow will not simply suffer from stagnant growth, but their survival will be threatened. This Special Issue on "Sustainable Transformation and Innovation in Organization Management" provides the sustainable change and innovation methods necessary for our lives and organizational management in a rapidly changing environment with various topics, such as the creation of new communication and collaboration spaces, positive motivation through gamification and feedback science, promotion of employee growth through edtech and facilitation, and traditional operation research approaches and technology innovation models.

Funding: This research was funded by National Research Foundation of Korea (NRF), grant number 2020R1A2B5B01001801.

Institutional Review Board Statement: Not applicable.

Informed Consent Statement: Informed consent was obtained from all subjects involved in the study.

Conflicts of Interest: The author declares no conflict of interest. The funders had no role in the design of the study; in the collection, analyses, or interpretation of data; in the writing of the manuscript, or in the decision to publish the results. 